\title{
The Impact of Metamemory on the EFL Students' Achievement at Taif University
}

\author{
Nasrah Mahmoud Ismaiel* \\ English Language Center, Deanship of Supportive Studies, Taif University, Saudi Arabia
}

Corresponding Author: Nasrah Mahmoud Ismaiel, E-mail: n.ismaiel@tu.edu.sa

\section{ARTICLE INFO}

Article history

Received: June 28, 2017

Accepted: August 14, 2017

Published: December 01, 2017

Volume: 6 Issue: 7

Special Issue on Language \& Literature Advance access: September 2017

Conflicts of interest: None Funding: None

\begin{abstract}
The purpose of the current research is to scrutinize the relationship between metamemory and EFL learners' achievement. The participants were 250 first year university students who were chosen from a large sample of the preparatory year Science and Humanities streams at Taif University, Taif, Saudi Arabia. The objective of the research is twofold: (a) to assess whether metamemory can predict English language skills achievement (listening, speaking, reading, and writing, and (b) to assess if there exist notable discrepancies between male and female students and the different academic streams (the science stream and the humanities stream) on the metamemory factors. Students` metamemory was measured by the Metamemory questionnaire (SMSQ) of Tonkovic and Vranic (2011). The results of this study show that metamemory is a good predictor of the EFL students` language learning skills achievement. It also indicates that there are differences between male and female students on the metamemory factors in favor of females. Furthermore, the findings reaffirm that there are differences between the academic streams, in favor of the science stream.
\end{abstract}

Key words: Metamemory, English Achievement, EFL College Saudi Students, Gender Differences, Academic Streams

\section{LITERATURE REVIEW}

\section{Introduction}

English language is an important subject, especially for university level students to prepare them for different specializations. However, it is a difficult subject for many students to understand, remember and reproduce. Many students need help to overcome their difficulties in learning English because many of the EFL learners lack awareness of and usefulness of learning strategies, especially in memory and metamemory. It has been also noted by the researcher that the EFL teachers find difficulty in teaching English for many reasons, for instance, many students lack of the appropriate learning strategies, lack of motivation and a lot of students have negative attitudes or beliefs towards learning English. Therefore, the current study has attempted to provide metamemory awareness to highlight some of the metamemory strategies that learners might use to overcome their challenges while learning English and to help them accomplish more. The findings of this study add to the previous research about metamemory awareness and its relation to EFL achievement. Furthermore, Eisenacher and Zink (2017) stated that, as a matter of fact, metamemory awareness delivers a basis for knowing one's memory mechanism and amendment of opinions about such abilities if needed, and for the application of tactics to achieve the task observations. For instance, metamemory has a role in knowing and mending wrong memories in a memory activity and helps the EFL learner to achieve more. Tactics are significant as they make the transfer of novel data easy into long-term memory (Belmont, Butterfield, \& Ferretti, 1982). Some investigations were done in Saudi Arabia to scrutinize the frequency of using EFL learning strategies in general. For instance, Alhaysony (2017), found that memory strategies were the least strategy used by students of some Arab nations that instead are mostly didactic and emphasize rote memorization.

\section{Metamemory}

Metamemory is generally the individuals' thoughts regarding their memory and the way memory works (Dunlosky and Thiede, 2013). Metamemory is usually designated as the comprehension the individual possesses of general memory working, along with the supervising and controling processes which permit individuals to rule their memory operation and what exists in it (Boucheron, 1993). Such a signification consists of two fields which point to the cognition of memory working and to supervising and control functions which are applied to do memory activities. (Fort, Adoul, Holl, Kaddour, \& Kamel, 2004). Hultsch, Hertzog, Dixon, and Davidson (1988) hold the view that the knowledge area per se has two types of subject: (a) real knowledge concerning activities, functions, and memory tactics; and (b) the individual's opinions regarding his/her own memory skills. Such writers 
also provide another kind belonging to memory-connected affect. The word metamemory points to the cognition the individual possesses regarding the development and application of memory and the individual's memory functions (Tonkovic \& Vranic, 2011).

Weed, Ryan, and Day (1990) deliver a more completed and newer specification of metamemory, pointing out that "Metamemory has been operationally defined, alternatively, as (a) verbalizable knowledge of person, task, and strategy variables affecting recall; (b) as self-regulation; and (c) as the effects of instructions incorporating executive control components or metacognitive acquisition procedures (p. 849)." As Weed et al.'s (1990) signification illustrates, metamemory is supposed to have two chief elements. These eleemnts are:

First, metamemory concerns stable knowledge of the variables that affect one's memory. This stable knowledge includes knowing about person, task, and strategy variables. These variables constitute (1) an understanding that the size and/or quality of a person's memory is affected by individual ability (person variables), (2) the relative difficulty of a task (task variables) and (3) the relative effectiveness of different strategies (strategy variables) (1990, p. 30).

An instance of individual comprehension is the knowledge, which in a certain period, the subject may recall something but not capable of remembering another. An instance of activity knowledge can be regarded the knowledge which a tougher activity (like remembering a list of 15 dictions) may be tougher to remember than an easier activity (remembering four dictions). Strategy knowledge is the kind of knowledge which grouping connected dictions together can be more influential than practice (repeating the list over and over) while trying to remember a long list of dictions.

\section{METAMEMORY AND ACADEMIC ACHIEVEMENT}

Achievement tests are exams which are interested in what the student had learned from knowledge, skills or abilities after the completion of receiving the study material (Mansoor, $2003,14)$. The relationship among overall metamemory and the way college students practiced in-class multiple choice tests was studied. Correlational and contingency analysis showed a positive relation among classroom practice and learners' suggested the application of organizational and self-testing tactics while they planned research for a free-recall activity (Leal, 1987).

Sinkavich, (1991), scrutinized the connections between class practice and five probable predictor variables. The methods that such variables connect to practice in a classroom acquisition context were assessed, with the supposition that attributional method and motive can be the greatest predictors of classroom activity. The variables were: (1) attributional style; (2) motivation; (3) self-testing ability; (4) information processing ability; and (5) use of metamemory. Subjects were 49 students from two graduate Educational Psychology courses who took two course examinations and one final examination. Students completed the Attributional Style Questionnaire and the Learning and Study Strategies
Inventory and made confidence predictions for each item on each examination. Results of a stepwise regression analysis indicate that the use of metamemory, motivation, and attributional style comprised the best subset of predictors for examination performance. Use of metamemory and motivation were significantly correlated with performance. Implications for adult instruction and future research are discussed. Four tables provide data, and an 85-item list of references is included.

Carr \& Borkowski, (1987), had studied connections between divergent thought, metamemory, success, and Intelligence Quotient (IQ) in talented fifth and sixth-graders $(\mathrm{N}=98)$ found that metamemory was related to both divergent thinking and achievement, suggesting that metamemory is autonomous from, yet necessary for, convergent and divergent thought that may underlie innovative success.

Metamemory may result in weak memory and weak achievement, while precise metamemory may improve memory and success (Dunlosky and Thiede, 2013).

Brown \& Smiley (1978) assessed learners' application of tactics and realized that active strategy applicants have high remembrance to those learners that merely re-read the text. Murphy and Schmitt (1987) realized that tactics like self-testing may be simply instructed, and they hold promise of being advantageous in various contexts.

Gearg, Adrales \& Klosterman (1990) observed stable correlation between metamemory and university success. The kinds of the fields where metamemory has been utalized have been properly shown in Klatzky's (1984) categorization of three general kinds of metamemory or consciousness of memory: Being conscious of the mental functions in which the individual is engaged (e.g., practice and categorization); consciousness of the contents which are saved in memory (the content the individual decides to cipher); and consciousness about memory as a human ability. AS Klatzky points out (1984) successful metamemory comprehension constitutes all the three stated styles.

Hasselhorn (1992) holds that metamemory creates a significant positive connection between memory supervising and memory activity. What this illustrates is that memory practice is the concentration of attention in metamemory research. In fact, research in such a field aims at enhancing memory practice by resorting to specific kinds of intervention. The aim of this investigation was to specify 1) if a metamemory theory for reading achievement would result in notably various outcomes from that of a skill-oriented theory, and 2) if short-term memory (STM) period is an autonomous and essential element or it is modified by the reader's metamemory comprehension. Seventy-six university learners were haphazardly opted and designated to the two experimental and a twelve-branch memory labyrinth and The Nelson's Reading Comprehension Test were applied as the STM period and the reading cognition exams respectively. The outcomes of the ANOVA applied help the idea that a metamemory theory is higher to a skill-oriented one. Moreover, they show that STM period is not an autonomous predictor of reading comprehension activity. In fact, the statistical data given by the application of the Point 
Biserial Correlation to the pre-tests of reading comprehension and STM period illustrate that there exists no notable go-togetherness among STM period and activity on reading comprehension exams. This research and the previous studies mentioned above have greatly assured metamemory help most students to accomplish their academic goals.

\section{Problem Statement}

The importance of this study arises from recent interest in the role played by metamemory in learning. Many studies have proven the need to direct attention toward the metamemory learning strategies that a student needs to enhance his own learning processes (Carr \& Borkowski, 1987; Gearg, Adrales \& Klosterman, 1990; Sinkavich, 1991). According to the researcher's extensive experience in the educational field, it was observed that some of the EFL students may not be competent for getting or achieving new data over the long term because of a lack of memory strategies. Discovering the greatest memory tactics for college learners has become important. Some students cannot remember information well. Moreover, they don't know how to effectively use learning strategies. Have you ever spent hours studying, only to have difficulty remembering information during the exam? This is a common occurrence among students and it happens because the students' lack of awareness of memory strategies. Therefore, the reasons that stand behind conducting this research are, first, to provide the students with memory strategies that teach the students how to take notes, study for tests, take tests, recall the information and apply their education to the real world. Secondly, the students' academic achievement as an output of educational processing and its relationship with the memory strategies is of great importance (Leal, 1987, Sinkavich, 1991).

Unfortunately, there is a scarcity of research on the impact of metamemory on the language elements (i.e. listening, speaking and reading, writing). Thus, this study comes to gauge the contribution of metamemory strategies, particularly on the achievement of EFL students in listening, speaking and reading, writing comprehension, especially in Saudi Arabia. The present study of metamemory, therefore, focuses on the contribution of this metamemory to achievement where it pertains to the four language elemnets, listening, speaking and reading writing achievement. Accordingly, this study addresses the following questions:

1. Can the meta-memory predict English language skills achievement (listening, speaking and reading writing)?

2. Are there any differences between male and female college students on the metamemory factors?

3. Are there any differences among academic streams on the metamemory factors?

\section{Purpose and Significance of the Study}

The present research has been conducted so as to deliver both instructors and students with thorough and complete comprehension concerning metamemory awareness. The current research aims to scrutinize the influence of these metamemory strategies on English language skills achievement and also to consider whether there are gender differences in metamemory factors and the academic streams.

\section{METHODOLOGY}

\section{Study Sample}

Pilot study

A hundred male and female learners were haphazardly selected from the college level Preparatory Year EFL nonEnglish major learners for the pilot research to specify the amount of time needed to do the surveys and to realize the validity and reliability of the tools. All the subjects were Saudis. Forty eight students from the Science stream (20 males and 28 females) and fifty two students from the Humanities stream (22 males and 30 females). Their age ranges from 18$28(\mathrm{M}=19.22, \mathrm{SD}=1.24)$.

\section{Participants}

Two-hundred fifty male and female students (135 males and 115 females- See Table 1) were haphazardly opted from the EFL preparatory year non-English major learners at Taif University. Their ages varied from 17-27 $(M=19.012, S D=0.976)$. All of them were Saudis. They all had taken 9 years of EFL instruction in grades 4-12 prior to their admission to Taif University. At the time of the study, the participants were studying English as a Foreign Lan-guage as a requirement of the Preparatory Year Program in which language elements such as reading, writing, lis-tening and speaking are studied for twelve hours weekly for two academic terms.

\section{INSTRUMENTATION}

\section{The Metamemory Questionnaire (SMSQ)}

Tonkovic and Veanic's (2011) metamemory questionnaire was used in this study. It is a self-report measure that includes fifty-seven items and with six subscales. According to item-subscale correlation, five items were deleted ( $4 \& 6,14$, $24,33)$, so the final version of the questionnaire contained fifty-two items instead of fifty-seven. The first subscale (subjective evaluation) includes 11 items (items 1 through 11), the second subscale (episodic memory) includes 12 items (items 12 through 23), and the third subscale (semantic memory) includes 14 items (items 24 through 37), the fourth subscale (memory for numbers) includes 6 items (items 38 through 43), and the fifth subscale (visuospatial memory) contains 5 items (items 44 through 48), and sixth subscale (Reminders) contains 4 items (items 49 through 52). It is a 5-point Likert scale, varied from 1 (completely disagree) to 5 (completely agree). Internal consistency was examined by Tonkovic and Vranic using Cronbach's alpha for SMSQ $(\alpha=0.92)$ and for every element (subjective assessment: $\alpha=0.85$; episodic memory: $\alpha=0.83$; semantic memory: $\alpha=0.82$; memory for numbers: $\alpha=0.81$; visuospatial memory: $\alpha=0.74$; reminders: $\alpha=0.78$ ). 


\section{Metamemory Questionnaire (SMSQ) Validly and Reliability in the Current Study}

The amended item-total correlation varied from 0.35 to $0.85(\mathrm{p}<0.01)$, recommending enough item validity. The amneded item-Subscale 1 (subjective assessment) correlation varied from 0.34 to $0.61(\mathrm{p}<0.01)$. For Subscale 2 (episodic memory) the correlation varied from 0.40 to 0.64 $(\mathrm{p}<0.01)$. For Subscale 3 (semantic memory) the correlation varied from 0.31 to $0.63(\mathrm{p}<0.01)$. For Subscale 4 (memory for numbers) the correlation varied from 0.65 to $0.73(\mathrm{p}<0.01)$. For Subscale 5 (visuospatial memory) the correlation varied from 0.67 to 0.84 ( $\mathrm{p}<0.01)$. For Subscale 6 (Reminders) the correlation varied from 0.72 to 0.78 $(\mathrm{p}<0.01)$. The correlation between elements varied from 0.23 to 0.63 , but the correlation among elements and total score varied from 0.35 to 0.85 . ( $p<0.05$ to $p<0.01$ ). And this shows that there exist positive correlations among the metamemory questionnaire for six subscales and showing that subscales of the metamemory tactics questionnaire illustrate high internal consistency in assessing the learners metamemory tactics.

The internal consistency was high for the total questionnaire $(\alpha=0.90)$, as well as for subscale $1(\alpha=0.66)$, subscale $2(\alpha=0.77)$, subscale $3(\alpha=0.80)$, subscale $4(\alpha=0.80)$, subscale $5(\alpha=0.79)$ and for subscale $6(\alpha=0.76)$. The mean total grade was 191.010 (S.D. $=23.264)$. The mean for subscale 1 was 42.410 (S.D. $=5.311)$, for subscale 2 was 50.070 $($ S.D. $=7.658)$, for subscale 3 was 49.130 (S.D. $=7.601)$ and for subscale 4 was 19.800 (S.D. $=4.688$ ), for subscale 5 was 18.190 (S.D. $=3.676)$ and for subscale 6 was 11.410 $($ S.D. $=4.665)$.

\section{Final Listening and Speaking Exams}

At Taif University, all Preparatory Year Program instructors constructed their Final exams for Listening and Speaking. There were ten multiple-choice questions on the exam. The teachers divided the total number of their students into two groups to maintain quietness and used two entirely different versions of the exam to avoid cheating. Audio materials to be tested on were taken from the textbook, so that all students were familiar with the material. The test questions were different, however, from the exercises in the book. By changing the questions from those in the book, comprehension was further challenged, measured, and enhanced. The students were asked to read the questions before listening. Then, the audio track was only played twice.

As for the final Speaking exam, each teacher chose several topics from material taught in class and the students were given one of the topics just before they were to speak, so that speaking would depend on their knowledge of the topic and so that they would speak spontaneously. They were graded on their ability to use what they learned in class and their ability to pronounce and form correct sentences and put them in a logical order.

This researcher used the scores of the Listening and Speaking final exams achievement for this research.

\section{English Language Learning Reading and Writing Achievement}

The final Reading and Writing exam was constructed by the ELC Testing Unit. Two hours were allocated at the end of the university term for the combined final reading and writing exams. There were 30 points for the Reading section of the exam, divided as follows: reading comprehension - 10 questions; vocabulary - 10 questions; and grammar - 10 questions. All questions were multiple choice questions with four possible answers, each. Each question was allocated 1 point. In addition to the Reading section, there were 10 points allocated for the Writing exam. The entire final exam reflected the unit lessons taught in class from the textbook and discussed by the teacher. Although the reading comprehension text came from the textbook, the questions were different from the exercises in the book, and therefore unfamiliar to the students, so that the testing of reading comprehension was maintained. There were two versions of the test (A and B) inside each envelope. The two versions of the exam had the same questions but the placement of the multiple choice answers was scrambled. In addition the placement of the questions on the exam was scrambled. The proctors distributed different versions of the test to rows of students alternately, attempting to avoid students' cheating. This researcher used the scores of the final Reading and Writing exams achievement.

\section{RESULTS}

\section{Test of Hypothesis One}

The first Hypothesis stated that the use of metamemory could predict students' listening, speaking, reading and writing achievement. To test the validity of the hypothesis, the Enter Method of regression analysis was conducted, in which the achievement scores on listening, speaking, reading and writing exams were independent variables and metamemory was the dependent variable.

By looking at Table 2, it is clear that correlation coefficient $r=0.486$ and the square of the correlation coefficient for listening is equal to 0.236 , for speaking $r=0.462$, the square of the correlation coefficient for speaking is equal to 0.214 , for reading and writing $r=0.555$, the square of the correlation coefficient for reading and write was equal to 0.306 , which confirmed that metamemory contributed to success in listening, speaking, reading and writing. So, this confirmed that success in listening, speaking, reading and writing could be predicted through the scores of metamemory. And this shows that $23.6 \%, 21.4 \%$, and $30.6 \%$, from the variance in listening, speaking and reading and writing explain respectively the important role of metamemory in language learning skills achievement.

Table 3 shows that the value of $F$ was statically significant for all language skills, $F=76.507 P=0.001$ for listening achievement, $F=67.397, P=0.001$ for speaking achievement, and $F=09.270, P=0.001$, for reading and writing combined. This verified the accuracy of the hypothesis that achievement could be predicted in the English language four skills from metamemory total score. 
It is seen from Table 4 that the values of $t$ are statistically significant for all the variables, which confirms that the metamemory is a good predictor of the English language skills achievement of listening, speaking, reading and writing together. The unstandardized equation of the regression can be written as follows:

Table 1. Stream * gender cross tabulation of the main study

\begin{tabular}{lccc}
\hline Streams & \multicolumn{2}{c}{ Gender } & Total \\
\cline { 2 - 3 } & Males & Females & \\
\hline Science & 68 & 64 & 132 \\
Humanities & 67 & 51 & 118 \\
Total & 135 & 115 & 250 \\
\hline
\end{tabular}

Listening $=3.492+0.021$ of the metamemory

Speaking $=4.555+0.019$ of the metamemory

Reading and writing $=23.302+0.07$ of the metamemory.

\section{Test of Hypothesis two}

The second hypothesis stated that there exist discrepancies between men and women in metamemory and its factors in favor of females. To test the validity of this hypothesis, a $t$-test was used for two independent groups as shown in the following table:

Table 5 indicates that there exist gender discrepancies between males and females in favor of females in the metamemory and its factors except in factor 4 (Memory for numbers) and 6 (Reminders) where there existed no discrepancies between men and women.

Table 2. Model summary for regression for the four language skills

\begin{tabular}{lcccc}
\hline Model & R & R square & Adjusted R square & Standard error of the estimate \\
\hline Listening & 0.486 & 0.236 & 0.233 & 1.2517 \\
Speaking & 0.462 & 0.214 & 0.211 & 1.1698 \\
Reading and writing & 0.553 & 0.306 & 0.303 & 3.4182 \\
\hline
\end{tabular}

Table 3. ANOVA for regression (English language skills scores as dependent variables, factors of metamemory as predictor)

\begin{tabular}{|c|c|c|c|c|c|}
\hline Model & Sum of squares & Df & Mean square & $F$ & Sig. \\
\hline \multicolumn{6}{|l|}{ Listening } \\
\hline Regression & 119.876 & 1 & 119.876 & 76.507 & 0.000 \\
\hline Residual & 388.580 & 248 & 1.567 & & \\
\hline Total & 508.456 & 249 & & & \\
\hline \multicolumn{6}{|l|}{ Speaking } \\
\hline Regression & 92.230 & 1 & 92.230 & 67.397 & 0.000 \\
\hline Residual & 339.374 & 248 & 1.368 & & \\
\hline Total & 431.604 & 249 & & & \\
\hline \multicolumn{6}{|c|}{ Reading and writing } \\
\hline Regression & 1276.727 & 1 & 1276.727 & 109.270 & 0.000 \\
\hline Residual & 2897.673 & 248 & 11.684 & & \\
\hline Total & 4174.400 & 249 & & & \\
\hline
\end{tabular}

Table 4. Coefficients of regression of English language skills

\begin{tabular}{|c|c|c|c|c|c|}
\hline \multirow[t]{2}{*}{ Model } & \multicolumn{2}{|c|}{ Unstandardized coefficients } & \multirow{2}{*}{$\begin{array}{c}\begin{array}{c}\text { Standardized } \\
\text { coefficients }\end{array} \\
\text { Beta } \\
\end{array}$} & \multirow[t]{2}{*}{$t$} & \multirow[t]{2}{*}{ Sig. } \\
\hline & B & Standard error & & & \\
\hline \multicolumn{6}{|l|}{ Listening } \\
\hline (Constant) & 3.492 & 0.434 & & 8.049 & 0.000 \\
\hline Metamemory score & 2.139E-02 & 0.002 & 0.486 & 8.747 & 0.000 \\
\hline \multicolumn{6}{|l|}{ Speaking } \\
\hline (Constant) & 4.555 & 0.406 & & 11.232 & 0.000 \\
\hline Metamemory score & $1.876 \mathrm{E}-02$ & 0.002 & 0.462 & 8.210 & 0.000 \\
\hline \multicolumn{6}{|l|}{ Reading and writing } \\
\hline (Constant) & 23.302 & 1.185 & & 19.666 & 0.000 \\
\hline Metamemory score & 6.980E-02 & 0.007 & 0.553 & 10.453 & 0.000 \\
\hline
\end{tabular}




\section{Test of Hypothesis Three}

The third hypothesis states that there were differences between Science Stream and Humanities Stream on the metamemory and its factors. To test the validity of this hypothesis, a t-test was applied for two autonomous groups. So, the comparisons between the two streams as illustrated in the below table:

Table 6 illustrates that there existed notable discrepancies between academic streams of Science and Humanities on metamemory and its factors except for the sixth factor (Reminders) in favor of the science stream.

\section{DISCUSSION}

It can be concluded that enlightening teachers about the importance of teaching students metamemory would have a positive impact on EFL students' awareness and use of metamemory strategies and consequently their EFL learning performance. The results of the present study confirm that metamemory predict of the four language elements of listening, speaking, reading and writing, and this confirms that the awareness of metamemory strategies can help college students to improve their memory and consequently, their English achievement. This study explores the effects of metamemory awareness on the EFL learners' English language skills academic achievement (listening, speaking and reading and writing. The present study found a strong association between metamemory and students' achievement. This concurs with the findings of some studies concerned with metamemory such as (Carr \& Borkowski, 1987, Gearg, Adrales \& Klosterman, 1990, Kalaimathi, \& Julius, 2012, Sinkavich, 1991) which also found that metamemory was related to achievement. Similarly, Weed, Ryan \& Day (1990) and Belmont, Butterfield, \& Ferretti, 1982,

Table 5. Gender differences in metamemory and its factors

\begin{tabular}{|c|c|c|c|c|c|c|c|}
\hline Metamemory strategies & Gender & $\mathbf{N}$ & Mean & Standard deviation & $t$ & Df & Sig. \\
\hline \multirow[t]{2}{*}{ Subjective evaluation } & Male & 135 & 36.4296 & 7.7484 & 2.891 & 248 & 0.004 \\
\hline & Female & 115 & 39.2348 & 7.5223 & & & \\
\hline \multirow[t]{2}{*}{ Episodic memory } & Male & 135 & 41.8889 & 11.7026 & 3.326 & 248 & 0.01 \\
\hline & Female & 115 & 46.4000 & 9.7394 & & & \\
\hline \multirow[t]{2}{*}{ Semantic memory } & Male & 135 & 44.8815 & 10.3722 & 2.732 & 248 & 0.007 \\
\hline & Female & 115 & 48.1391 & 8.4769 & & & \\
\hline \multirow[t]{2}{*}{ Memory for numbers } & Male & 135 & 18.2963 & 4.8532 & 1.589 & 248 & 0.113 \\
\hline & Female & 115 & 19.2609 & 4.6999 & & & \\
\hline \multirow[t]{2}{*}{ Visuospatial memory } & Male & 135 & 15.7407 & 5.0386 & 2.604 & 248 & 0.01 \\
\hline & Female & 115 & 17.2261 & 3.7558 & & & \\
\hline \multirow[t]{2}{*}{ Reminders } & Male & 135 & 11.1556 & 4.1247 & 0.322 & 248 & 0.747 \\
\hline & Female & 115 & 11.3304 & 4.4421 & & & \\
\hline \multirow[t]{2}{*}{ Total score of metamemory } & Male & 135 & 168.3926 & 34.4743 & 3.319 & 248 & 0.001 \\
\hline & Female & 115 & 181.5913 & 28.4006 & & & \\
\hline
\end{tabular}

Table 6. The differences between academic streams

\begin{tabular}{|c|c|c|c|c|c|c|c|}
\hline Metamemory strategies & Stream & $\mathbf{N}$ & Mean & Standard deviation & $t$ & Df & Sig. \\
\hline \multirow[t]{2}{*}{ Subjective evaluation } & Science & 132 & 39.939 & 7.268 & 5.011 & 248 & 0.001 \\
\hline & Humanities & 118 & 35.237 & 7.560 & & & \\
\hline \multirow[t]{2}{*}{ Episodic memory } & Science & 132 & 47.485 & 9.263 & 5.647 & 248 & 0.001 \\
\hline & Humanities & 118 & 40.025 & 11.592 & & & \\
\hline \multirow[t]{2}{*}{ Semantic memory } & Science & 132 & 49.508 & 8.497 & 5.748 & 248 & 0.001 \\
\hline & Humanities & 118 & 42.881 & 9.7281 & & & \\
\hline \multirow[t]{2}{*}{ Memory for numbers } & Science & 132 & 20.121 & 4.446 & 5.045 & 248 & 0.001 \\
\hline & Humanities & 118 & 17.195 & 4.722 & & & \\
\hline \multirow[t]{2}{*}{ Visuospatial memory } & Science & 132 & 18.008 & 3.805 & 6.0255 & 248 & 0.001 \\
\hline & Humanities & 118 & 14.653 & 4.667 & & & \\
\hline \multirow[t]{2}{*}{ Reminders } & Science & 132 & 10.864 & 3.879 & 1.463 & 248 & 0.145 \\
\hline & Humanities & 118 & 11.653 & 4.642 & & & \\
\hline \multirow[t]{2}{*}{ Total score of metamemory factors } & Science & 132 & 185.922 & 28.005 & 6.359 & 248 & 0.001 \\
\hline & Humanities & 118 & 161.641 & 32.365 & & & \\
\hline
\end{tabular}


found that metamemory training improves the memory of a learner and knowing the metamemory strategies are important for the students. In the same vein, Grammer, Purtell, Coffman and Ornestein, (2012) found out that metamemory strategies predict children's performance and students who employed more metamemory strategies scored higher on assessments than students who employed fewer metamemory strategies and the study of Sinkavich (1991) and Magno (2008), that reaffirms that metamemory was a good predictor of the students' English written proficiency and academic achievement and a predictor of accuracy of memory tasks (Kvavilashvili \& Ford (2014).

Concerning the differences between men and women in university learners on the metamemory factors, the findings showed that there are differences on the metamemory factors and total score except in factors $4 \& 6$ in favor of females. This result mirrors the prior studies of Callaghan, Fallon, Judy, Lucas, \& Weiler, (2002), Chipman, Kimura, \& Fraser, (1998) who reported that women use more strategy metamemory tasks and found that women performed better than men on both recall and recognition tests. Females therefore, have an advantage on verbal recall tasks (Chipman, Kimura, \& Fraser, 1998). In addition, this finding agrees partially with of Tonkovic and Vranic (2011) who revealed there is a significant influence of gender on all elements except for subjective memory and memory of numbers. However, this result does not get along with the results of Beqaie (2013) who found that there existed no discrepancies between men and women in university students on the metamemory factors.

In regards to the differences between academic streams on the metamemory factors, the results revealed that there were differences between the students of humanities and science streams in favor of the science stream students. It is possible that this is due to the nature of scientific studies and the necessity for accurate details, which often requires a lot of the understanding of information, which is based on remembering meanings. In addition, the students admitted into the science stream at the university have requirements higher than those for the humanities stream, such as a higher GPA and higher scores on the General achievement and abilities test. This finding is consistent with the study of Beqaie (2013) which concluded that there were differences between academic streams for the sake of the science stream.

\section{CONCLUSION}

In summary, metamemory is the perception of one's memory processes. Different theories describe different components of metamemory. Available literature has confirmed that both descriptive and imperial researches have verified the positive impact of metamemory on EFL learning. All in all, it was found by many researchers that further investigation of the level of metamemory awareness for EFL learners was needed because of the disappointing level of EFL learning strategies awareness in general and metamemory awareness in particular among both students and teachers. The outcomes of the present research would produce baseline data and give insights to decision makers in departments of higher education and in the Saudi Ministry of Education. It would also work as a baseline and foundation for more research on this area in Saudi Arabia. When the college staff is aware of the advantage of using metamemory learning strategies, they can support the students' quality academic performance and improve their English language achievement, and then they may be more willing to give some class time to these metamemory strategies. This study is also meaningful because its findings can help teachers, researchers and school administrators better understand of how the EFL students improve their academic English achievement.

\section{REFERENCES}

Alhaysony, M. (2017). Language Learning Strategies Use by Saudi EFL Students: The Effect of Duration of English Language Study and Gender. Theory and Practice in Language Studies, Vol. 7, No. 1, pp. 18-28, DOI: http:// dx.doi.org/10.17507/tpls.0701.03.

Barbara E. Moely, Kevin A. Santulli, and Nimala Rab (1985). Teachers' Expectations for Memory and Metamemory Skills of Elementary Such Childten. Paper presented at the Biennial Meeting of the Society for Research. Child Development Toronto, N, V. Ontario, Canada, April 2528, 1985).

Belmont, J. M., Butterfield, E. C., \& Ferretti, R. P. (1982). To secure transfer of training instruct self-management skills. In D. K. Detterman \& R. J. Sternberg (Eds.) How and how much can intelligence be increased? Norwood, NJ: Ablex Publishing Corp.

Beqaie, N. A. (2013). Metamemory and Its Relation to Cognitive Flexibility in a Sample of First Year Students. Journal of Educational and Psychological Sciences, 14, (3), 329-358.

Borkowski, J. G.; Ryan, E.B.; kurtz, B.E. and Reid, M.K. (1983) Metamemory and metalinguistic development: Correlates of children's intelligence and achievement. Bulletin of the Psychonomic Society, 21 (5), 393-396.

Boucheron, C. (1993). Mémoire, métamémoire et vieillissement. Unpublished thesis, University Nancy 2, France.

Brown, A. L. (1978). Knowing when, where and how to remember: a problem of metacognition. In R. Glaser (ed.), Advances in instructional psychology, Volume 1, pp. 77-165. Hillsdale, NJ: Lawrence Erlbaum Associates.

Bruce, A. J.; Cox, M. O. (1983). Metamemory and Structure: Spelling. Educational Research Quarterly, 8 (2), 38-43.

Callaghan, A. D., Fallon, L.J., Judy, S.E., Lucas, S.A., \& Weiler, B.W. (2002). Metamemory as a Function of Gender-Related Stimuli. University of Florida. Retrieved November 4, 2002, from http://www.psych.ufl. edu/levy/96 4.html.

Carr, M. \& Borkowski, J. G (1987). Metamemory in Gifted Children. Gifted Child Quarterly, 31 (1), 40-44.

Chipman, K., Kimura, D., \& Fraser, S. (1998). An Investigation of Sex Differences on Incidental Memory for Verbal and Pictorial Material. Learning \& Individual Differences, 10, 259-273. 
Dunlosky, J. and Thiede, K.W. (2013). Metamemory. (pp. 283-298) is from The Oxford Handbook of Cognitive Psychology, edited by Daniel Reisberg (2013), is reproduced by permission of Oxford University Press. doi:10.1093/oxfordhb/9780195376746.013.0019.

Eisenacher, S. \& Zink, M. (2017). The Importance of Metamemory Functioning to the Pathogenesis of Psychosis Front Psychol. 8, 304.

Flavell, J. H, Wellman, H. M. (1975). Metamemory. Paper presented at the Annual Meeting of the American Psychological Association (83 ${ }^{\text {rd }}$, Chicago, Aug. 30-Sept. 3, 1975).

Fort, I., Adoul, L., Holl, D., Kaddour, J. \& Kamel, G. (2004). Psychometric Properties of the French Version of the Multifactorial Memory Questionnaire for Adults and the Elderly. Canadian Journal on Aging/La Revue canadienne du vieillissement 23 (4), 347 - 357.

Kvavilashvili, L.\& Ford, R.M. (2014). Metamemory prediction accuracy for simple prospective and retrospective memory tasks in 5-year-old children. Journal of Experimental Child Psychology 127, 65-81.

Geary, D C 1, Klosterman I H, Adrales K. (1990). Metamemory and academic achievement: testing the validity of a group-administered metamemory battery. $J$ Genet Psychol. 151(4), 439-450.

Grammer, J.K. Purtell, K.M. Coffman, J.L. and Ornestein,P. A. (2012). Relations between Children's Metamemory and Strategic Performance: Time-Varying Covariates in Early Elementary School. J Exp Child Psychol. 108(1), 139-155.

Hasselhorn, M. (1992). Task dependency and the role of category typicality and metamemory in the development of an organizational strategy. Child Development, 63, 202-214.

Hultsch, D.F., Hertzog, C., Dixon, R.A., \& Davidson, H. (1988). Memory self-knowledge and self-efficacy in the aged. In M.L. Howe \& C.J. Brainerd (Eds.), Cognitive development in adulthood: Progress in cognitive development research (pp. 65-92). New York: Springer.

Kalaimathi, D. H. \& Julius, R. A. (2012). Effect of Metamemory Strategies on Learning Bio-Chemical Cycle among Higher Secondary School Students. INDIAN JOURNAL OF APPLIED RESEARCH, 2(1), 1-5.

Klatzky, R. L., \& Forrest, F. H. (1984). Recognizing familiar and unfamiliar faces. Memory \& Cognition, 12, 60-70.

Leal, L. (1987). Investigation of the Relation Between Metamemory and University Students' Examination Performance. Journal of Educational Psychology, 79 (1), 35-40.

Lockl, K, Schneider, W. (2007). Knowledge about the Mind: Links between Theory of Mind and Later Metamemory. Child Development, 78 (1), 148-167.

Magno, C.(2008). Reading strategy, amount of writing, metacognition, metamemory, and apprehension as predictors of English written proficiency. Asian EFL Journal: Professional Teaching Articles. Available at SSRN: http:// ssrn.com/abstract $=1429342$.

Schnieder, W., Schlagmuller, M., Vise, M. (1998). The Impact of Metamemory and Domain-Specific Knowledge on Memory Performance. European Journal of Psychology of Education, 13 (1), 91-103.

Sinkavich, F.J. (1991). Metamemory, Study Strategies, and Attributional Style: Cognitive Processes in Classroom Learning. Avalable at ERIC Number: ED331846.

Tonkovic, M. \& Vranic, A. (2011). Self-evaluation of memory systems: Development of the questionnaire. Ag-ing \& Mental Health. Applied Cognitive Psychology 29(2), 244-252.

Weed, K., Ryan, E. B., \& Day, J. (1990). Metamemory and attributions as mediators of strategy use and recall. Journal of Educational Psychology, 849-855. 